\title{
ô Cincuenta paradojas del siglo XX
}

Ricardo Ribera

Universidad Centroamericana "José Simeón Cañas"

Resumen: El presente ensayo hace un enfoque de acontecimientos relevantes de la primera mitad del siglo XX utilizando un procedimiento atractivo y novedoso: mediante anécdotas y curiosidades, que despiertan el interés del lector y consiguen eludir el consabido aburrimiento que las temáticas históricas suelen provocar entre las jóvenes generaciones. Lo superficial puede ser una vía de acceso a cuestiones de una mayor profundidad y lo aparentemente irrelevante un camino a lo esencial. La metodología para la exposición mantiene, sin embargo, la finalidad primordial de los estudios históricos: la interpretación de los hechos por encima de la erudición del dato, la reflexión sobre su significado antes que una estéril memorización de eventos. Enfocada así, si la historia algo enseña, es a pensar críticamente.

Abstract: This essay makes an overview of relevant events of the first half of the Twentieth Century deploying an innovative and appealing procedure. It uses anecdotes and curiosities that engage the reader and avoid the boredom that historic topics provoke among the younger generations. The superficial can be a way of access to more profound issues and the irrelevant a way to the essential. This methodology mantains, nevertheless, the primordial goal of historical studies: the interpretation of facts over the erudition of data, reflection on meaning before a fruitless memorization of events. Addressed in such a manner, if history is to teach something, it is to think critically.

Palabras clave: Historia contemporánea, colonialismo, imperialismo, comunismo, revolución rusa, guerras mundiales.

Keywords: Contemporary history, colonialism, imperialism, comunism, Russian revolution, world wars 
La idea de hilvanar este texto ha surgido directamente de la experiencia en el aula universitaria. Posiblemente conserve mucho del estilo oral, propio de la exposición del docente. Ojalá mantenga también algo de su espontaneidad y frescura originales. Puesto sobre el papel el pensamiento tiende a solidificarse, a petrificarse como fósil y a perder vitalidad. No obstante, es su única forma de quedar y de ofrecerse más allá de la fugacidad del habla y del estrecho círculo de los participantes del diálogo. Contar con un texto escrito, además, puede ser para los estudiantes un apoyo importante.

La conveniencia de buscar trucos didácticos en la práctica de la enseñanza se vuelve pura necesidad cuando a uno le toca impartir una "asignatura imposible", como ésta que pretende revisar la historia mundial contemporánea y al mismo tiempo poner en práctica los métodos del análisis histórico; casi nada. ¿Cómo traer el mundo al aula y hacer que el siglo entero nos quepa en apenas dieciséis semanas?

¿Cómo "enseñar" historia -en caso de que la historia pueda enseñarse - y cómo hacerlo sin incurrir en el tedio que habitualmente los temas del pasado generan entre los jóvenes? Por otro lado, ¿cómo hacer para desarrollar en el estudiante la capacidad de análisis? O sea, lograr que el alumno sea capaz de analizar por sí mismo. Es decir, que aprenda a pensar. Suena muy tonto o tal vez muy presuntuoso, pero si se medita bien el asunto se caerá en la cuenta de que justamente de esto se trata. o por muy trivial o por demasiado ambicioso, el objetivo principal de esta asignatura nos coloca en una situación de casi imposibilidad.

Por donde se enfoque la cosa, bien sea desde sus contenidos -inabarcables-, bien sea desde sus objetivos -inalcanzables-, la materia nos hace transitar por terreno resbaladizo; es el territorio de la paradoja. Pues bien, ante estos retos ¿qué mejor que usar la paradoja contra sí misma? O sea, ¿por qué no ensayar - desde lo que de paradójico tienen los acontecimientos históricos- un método para iluminar lo que en ellos subyace?

Entiéndase que no estamos usando el término paradoja como sinónimo de la palabra contradicción. Ésta aparece por la naturaleza de la historia, por su forma de proceso dialéctico, que se desarrolla movido por la contradicción y por la oposición de contrarios.

La paradoja algo tiene que ver con la dialéctica, pero sólo en un nivel mucho más superficial. Es simplemente el terreno de lo extraño, de lo desconcertante, de lo anecdótico o lo sorpresivo que, por serlo, despierta nuestra atención y nos mantiene en tensión 
expectante. Lo accesorio se presenta así como un camino a lo esencial.

De sorpresa en sorpresa, de broma en broma, la historia nos contempla desde sus paradojas con un semblante menos severo de lo habitual. Esa señora parece entonces sonreírnos con ironía, e incluso se permite hacernos un guiño de complicidad.
La paradoja existe en la historia, la hallamos más profusamente de lo que podríamos esperar. Familiarizarnos con ella nos ayudará a entender mejor la contradicción, valga pues como ejercicio didáctico. Lo trivial aparecerá escondiendo lo profundo, facilitando su acceso.

\section{El siglo XX no comenzó en 1901}

Si aceptamos el concepto "tiempo histórico", que es diferente al tiempo en su acepción cotidiana o "tiempo calendario", debemos entender que períodos temporales como los siglos, las décadas o los años, vendrán determinados por los acontecimientos y el significado que les atribuyamos. Así habrá "años históricos" (como el caso de 1992, que para la historia salvadoreña es "el año de la paz"), "décadas históricas" (como "los felices veinte" para países desarrollados del hemisferio norte, década que abarcaría de 1919 a 1929, cuando la crisis económica mundial le pone fin) y de igual forma "siglos históricos" (así el "siglo de las Luces", el siglo del Barroco, entre otros).

La definición usual de siglo como centuria, o período de cien años, se flexibiliza desde el punto de vista histórico. No va a tener exactamente esta cantidad de años y tampoco va a comenzar en un año termi- nado en uno y a concluir en un año terminado en cero, así como tales años no necesariamente iniciarán el $1^{\circ}$ de enero y terminarán el 31 de diciembre. Las fechas de inicio y final, así como la cantidad de años del siglo, vienen determinados por los acontecimientos relevantes y por el significado histórico global del mismo. En el caso del siglo XX, lo hemos definido históricamente como "el siglo de Estados Unidos, el siglo del imperialismo y el siglo de la globalización". El siglo XX ha consistido en el ascenso de Estados Unidos hasta alcanzar la hegemonía mundial. Al mismo tiempo, dicha potencia ha impuesto la modalidad del imperialismo en las relaciones mundiales de dominación, así como la globalización de tipo neoliberal al realizar una tendencia de la historia económica de la humanidad. Cuestiones de forma, como las fechas de su arranque y de su acabamiento, se supeditan a tal caracterización. Hay que buscar hechos 
y acontecimientos que simbolicen esa nueva voluntad de la potencia norteamericana para señalar el arranque del siglo.

\section{El siglo XX comenzó en 1898}

En ese año, el gobierno estadounidense decidió aprovechar un incidente (el incendio fortuito en un buque norteamericano fondeado en La Habana) para acusar a las autoridades españolas de haber sido responsables del mismo y, tras provocar una oleada de indignación entre la opinión pública estadounidense, declararle la guerra a España. Estados Unidos se inmiscuía en el proceso de guerra independentista de los patriotas cubanos, a quienes arrebataba su probable triunfo sobre la metrópoli ibérica, pues la independencia de Cuba pasaba a ser consecuencia de la derrota española ante el mayor alcance y poder de fuego de la marina de Estados Unidos. Como resultado, Cuba dejaba de ser colonia española pero no obtenía la plena independencia: la enmienda Platt reducía la soberanía cubana, dejaba a Cuba sin política exterior y quedaba la isla sometida a una especie de protectorado estadounidense. Algo similar ocurría con Puerto Rico, prácticamente anexionado por la gran potencia.

Estados Unidos no se limitó a expulsar a España del continente americano, también arremetió contra su posesión asiática: atacó al ejército español en Filipinas. Inicialmente se apoderó del archi- piélago, pero después rectificó. Se limitó a construir bases militares en su territorio y permitió el autogobierno de la antigua colonia española. También en Cuba se arrogó el derecho de crear una base militar en la zona de Guantánamo. En el mismo año promovió una consulta entre la población de las islas Hawái, que votó favorable a ser parte de Estados Unidos, lo que fue utilizado para levantar asimismo una gigantesca base naval en Pearl Harbor, en mitad del océano Pacífico. También accedió a la oferta del zar ruso y le compró Alaska. Estados Unidos salía de su tradicional aislamiento y respaldaba su comercio mundial con presencia militar a escala global. Su fuerza naval se dislocaba en varias flotas de guerra y estaba permanentemente en los diferentes océanos y mares del mundo. Era la política imperialista: el capitalismo en esta nueva fase de desarrollo renuncia a colonizar otras regiones y pueblos (resulta muy costosa su administración) centrándose en asegurar las fuentes de materias primas, los mercados para sus productos, las oportunidades de inversión para su capital. Los gobiernos que no acepten someterse arriesgan ser políticamente desestabilizados 0 directamente agredidos. 


\section{El reparto imperialista del mundo: ¿civilización o barbarie?}

Pretendía justificarse por "llevar civilización" a los pueblos atrasados, cuando en realidad extendía la "barbarie" de la violencia y aumentaba el peligro de guerra. En 1885 se realizó en Berlín un congreso para que las potencias europeas se pusieran de acuerdo en ocupar la totalidad del continente africano para evitar roces entre ellas. Se estaba completando lo que se llamó "el reparto del mundo". Gran parte de América Latina había alcanzado la independencia en las primeras décadas del siglo XIX, pero en lo que restaba del siglo se producía el movimiento inverso: la casi totalidad de Asia y África terminaría siendo sometida a la condición de colonia por las potencias europeas. Es así como -a comienzos del siglo XX- ocho países europeos se habían repartido prácticamente la totalidad del planeta. La tendencia a la expansión, su voracidad imperialista, no se detenía y muy pronto empezaron las tensiones entre las diferentes potencias colonialistas.

\section{Los viejos imperios coloniales buscaban expandirse 0 , por lo menos, mantenerse mientras las nuevas potencias aspiraban a conseguir sus propias colonias, de tal forma, el choque de intereses era inevitable}

Los mayores imperios coloniales eran, con gran diferencia, el británico y el francés. Gran Bretaña dominaba sobre 367 millones 300 mil habitantes, en un territorio de 31 millones 410 mil kilómetros cuadrados. Francia, por su parte, controlaba 10 millones 980 mil kilómetros cuadrados, con una población aproximada de 50 millones de personas. Les seguía el Imperio holandés que se imponía sobre 37 millones 800 mil seres humanos, pero en un territorio de "sólo" 2 millones de kilómetros cuadrados. La siguiente potencia por el tamaño de sus posesiones en África era la pequeña Bélgica, cuyo monarca, el rey Leopoldo, con el subterfugio de promover las investigaciones geográficas y etnográficas, logró que el resto de Europa le aceptara la soberanía sobre el inmenso Congo belga: 2 millones 300 mil kilómetros cuadrados, con 19 millones de nativos e ingentes riquezas mineras. Alemania obtuvo territorios al sur del lago Victoria (África oriental alemana o Tanganica, la actual Tanzania) y en el suroccidente (África occidental alemana, la actual Namibia) que sumaban 2 millones 600 mil kilómetros cuadrados, y dominando sobre 12 millones de africanos. Portugal aún retenía dos colonias, Angola y Mozambique, que representaban 
unos 2 millones de kilómetros cuadrados con una población de 7 millones 600 mil habitantes. España apenas conservaba un territorio costero frente las islas Canarias (Río de Oro y Sáhara occidental). Italia, en cambio, iniciaba su expansión colonial sobre Libia, Eritrea y, por breve tiempo, Etiopía.

Si en 1876 estaba colonizado apenas el $10.5 \%$ de África, para 1900 ya lo estaba el $88.9 \%$. Las potencias coloniales europeas habían pasado de controlar sólo ciertas zonas costeras africanas a disputar el control de grandes extensiones del interior. A veces ni siquiera habían explorado previamente los territorios que reclamaban; simplemente trazaban líneas sobre el mapa para dibujar el perímetro de las nuevas posesiones coloniales. En el caso británico, sus posesiones en África se extendían de norte a sur, desde la costa mediterránea de Egipto hasta Sudáfrica, en el extremo sur del continente, incluyendo Sudán, Kenia y Rhodesia. Francia, por su parte, extendía su dominio colonial desde Marruecos y Argelia hacia el sur, abarcando toda la zona del Sáhara y el Sahel, el África occidental francesa y el África ecuatorial francesa, hasta el golfo de Guinea.

Las viejas potencias pretendían ampliar todavía más sus dominios y las nuevas potencias aspiraban a sus primeras posesiones coloniales, por ejemplo: Bélgica, Italia y Alemania. No se trataba sólo de explotar recursos y de lograr beneficios económicos: poseer colonias se había convertido en una cuestión de prestigio. También Austria, Rusia y Japón buscaban expandirse.

\section{Los incidentes en África y los Balcanes reflejaban las políticas de expansión que eran propias de la naturaleza misma del imperialismo}

En el norte de África se dieron dos coyunturas sucesivas de crisis -en 1906 y 1911 - en torno a la cuestión de Marruecos. Éste es disputado por Alemania, a la que Francia cede finalmente un territorio de 265 mil kilómetros cuadrados en el Congo, cerca del golfo de Guinea, a cambio de ver reconocida su tutela sobre Marruecos, así como ya la había conseguido antes sobre Argelia y Túnez.
Las tensiones en la región europea de los Balcanes, sin embargo, no resultaban tan fáciles de solucionar. Allí chocaban por sus intenciones de expansión dos imperios: el austrohúngaro y el ruso. Austria, contando con el incondicional respaldo de Alemania, se anexionó Bosnia en 1908. Era coherente con su tendencia a expandirse hacia el sur, para debilitar así aún más al Imperio turco otomano, 
el cual iba en retroceso, e impedir el fortalecimiento de Serbia como nueva potencia regional en los Balcanes. El problema es que las rivalidades en la región habían despertado el interés y codicia de grandes potencias continentales.
Rusia ve en Serbia un aliado para asegurar la salida de su flota desde el mar Negro, por lo que quiere frenar la expansión de Austria y debilitar a Turquía. Alemania respalda a Turquía, pues tiene ahí grandes inversiones.

\section{A veces la guerra se vuelve inevitable... sobre todo cuando nadie desea evitarla}

Se dice que el atentado de Sarajevo, donde fue asesinado el archiduque Francisco Fernando, heredero del trono austríaco, provocó la guerra. En todo caso, fue solamente como la chispa que en un polvorín mal cuidado provoca el estallido, como el detonante de la bomba, como el catalizador en una reacción química. El incidente por sí mismo no explica el enorme cataclismo histórico que desencadenó.

El 28 de junio de 1914, un estudiante serbio -vinculado a "La Mano Negra"- una sociedad secreta nacionalista serbia disparaban sobre el heredero del Imperio austrohúngaro. Austria acusa de inmediato a Serbia y le presenta un ultimátum durísimo, claramente inaceptable. Entre el 28 de julio al 4 de agosto, todas las grandes potencias europeas entran en guerra unas contra otras: Austria le declara la guerra a Serbia, Rusia se la declara a Austria, Alemania a Rusia, Rusia a Turquía, Francia a Alemania y, finalmente,
Inglaterra a las dos "potencias centrales": Alemania y AustriaHungría.

El incidente de Sarajevo puede ser visto históricamente como algo accidental. Pero no parece accidente que haya sido justo en la complicada región de los Balcanes donde se dieron las primeras llamas del gran incendio que consumiría Europa y parte del mundo. Se ha convertido casi en un lugar común hablar del "polvorín balcánico". Región de frontera por excelencia, ahí han coincidido -porque hasta ahí llegaron en su expansión- tres grupos étnicos, tres lenguas y tres religiones. Todo ello entremezclado. No son tres mundos: son tres por tres por tres. Una gran riqueza si hay tolerancia; si no la hay, un caos. Región de límite de culturas. Región, por ello mismo, de guerras interminables. Todavía ahora no terminan. Es algo así como la región ideal para empezar una gran guerra. 


\section{7. ¡Hagamos la guerra para ganar la paz!}

Ese desarrollo de los acontecimientos es responsabilidad en parte de las dirigencias políticas. Los líderes de la socialdemocracia de la época, de cada partido nacional agrupado en la llamada Segunda Internacional, demostraron no estar a la altura de los tiempos. En especial los alemanes, con una poderosa formación política que constituía las dos terceras partes de los marxistas europeos de ese tiempo. Al momento de la decisión en el parlamento, olvidando su propaganda anterior, votaron a favor de los créditos de guerra y llamaron a la unidad nacional "contra el enemigo de la patria". Se imposibilitaba la Revolución alemana, pese a la maduración de las condiciones, al adoptarse por la vanguardia tal posición. "Cuando la patria está en peligro... hay que anteponer la unidad de la Nación." No supieron resistir la corriente de opinión pública favorable a la guerra y ante el temor de quedar desacreditados, optaron por claudicar.

\section{Se dice "los amigos de mis amigos son también mis amigos"... pero, ¿qué pasa con los enemigos?}

En las alianzas - por ejemplo en la alianza matrimonial- uno incorpora las amistades del otro a su propio mundo, pero también carga con sus acreedores y enemigos. Igual, con mayor razón, ocurre entre los Estados. De tal modo, hacerse con un nuevo aliado puede echar a perder las viejas amistades, en especial si éstas tienen problemas con aquél. Estratégica la alianza alemana con el Imperio austrohúngaro, rival de la Rusia imperial en su expansión balcánica; pero traía los costos de un enfriamiento en la relación del káiser alemán con el zar ruso. Mientras esto ocurría se cumplía la profecía de Marx: la revanchista Francia, archirrival de Alemania, buscaba atraerse a Rusia. Incluso, la penetración de la economía turca por la poderosa Alemania provocaba nuevos roces con Rusia, que rivalizaba con Turquía una salida al Mediterráneo.

\section{9. “La victoria de Alemania sobre Francia arrojará a ésta a los brazos de Rusia"}

No le entendieron en aquel momento. Se rieron. Era proverbial la amistad entre el zar de todas las Rusias y el emperador alemán. Rusia y Alemania eran viejos aliados, siempre dispuestos a 
pelear juntos y juntos repartirse los despojos de la maltratada Polonia, a la que en mala hora el destino puso geográficamente en medio de dos imperios en plena expansión territorial. Por eso resultaban tan increíbles las previsiones de Marx. Sin embargo, las palabras del agudo analista se iban a cumplir casi medio siglo más tarde.

El cambio del escenario internacional era en parte fruto de la guerra franco-prusiana -en la que Francia salió humillada-, y en parte fruto de la unidad pangermánica (el Imperio prusiano-alemán y el Imperio austrohúngaro, bajo la hegemonía de Berlín). Las dos cosas eran mérito de Bismarck, forjador de la unidad alemana y un verdadero genio en el arte de combinar lo militar con lo diplomático. Tradicionalmente, franceses y alemanes habían sido enemigos y a lo largo de la Edad Media habían sostenido varias guerras. Siempre Francia había tenido a su favor el mayor tamaño de su población. Ahora esa relación se había invertido: Alemania tenía 68 millones de habitantes, mientras la demografía de Francia había quedado rezagada, con unos escasos 40 millones de franceses.

\section{Se imponen los intereses económicos y los cálculos políticos cuando la hegemonía mundial está en juego}

Gran Bretaña dominaba ampliamente el mercado mundial con su poderosa fuerza naval al servicio de proteger su comercio y la riqueza de su imperio colonial. Veía complacida las interminables luchas europeas que impedían que alguna de esas potencias llegara a disputarle su predominio mundial. No tenía un interés ni a favor ni en contra de unos $u$ otros. A Inglaterra lo que le interesaba era que ninguna de las potencias continentales se impusiera con tanta claridad que llegase a ser una amenaza para su - hasta entonces- indiscutida hegemonía mundial. Las "potencias centrales" (Alemania unida a Austria-Hungría) tendían a romper a su favor el equilibrio. Además, su fulgurante crecimiento económico era amenazante. Las exportaciones germanas estaban aumentando aceleradamente a un ritmo del $300 \%$ y las británicas, aunque también crecían, lo hacían a un modesto $18 \%$. Inglaterra decidió entonces intervenir en apoyo de la amenazada Francia. Pese a su tradicional enemistad con los franceses y a la serie de guerras que ambos países habían protagonizado, el cálculo político se impuso: frenar a Alemania antes de que ésta se hiciese demasiado poderosa. 


\section{Quienes la vivieron no la llamaron la Primera Guerra Mundial}

\begin{abstract}
Ése es el nombre que ha recibido históricamente después de que otra gran confrontación militar, que fue bautizada desde su inicio como la Segunda Guerra Mundial, indujera a cambiarle nombre a la anterior. Hasta entonces ésta había sido conocida como "la Gran Guerra". No hubo conciencia de su alcance mundial hasta que llegó a su término, dado que la confrontación que se había iniciado en suelo europeo había ido extendiendo el teatro de operaciones a los países coloniales, y al final había participado también Estados Unidos. No se
\end{abstract}

tenía recuerdo en la historia de una carnicería de tal dimensión. Millones de muertos en combate, millones de víctimas civiles, millones en pérdidas económicas y en infraestructura destruida. La civilización industrial, encabezada justamente por las potencias contendientes, puso todo su poderío al servicio de la destrucción y demostró ser un poder formidable. Era la lucha por la cuota de cada burguesía nacional en el mercado mundial. El capitalismo demostraba ser un sistema capaz de atrocidades nunca vistas.

\section{Se decía que sólo la revolución podía evitar la guerra. No hubo revolución. Hubo guerra. Pero de la guerra imperial surgió triunfante la revolución}

El período de 1914 a 1918 muestra, en su contenido, duplicidad de acontecimientos - guerra mundial $\mathrm{y}$ al mismo tiempo despliegue $\mathrm{y}$ triunfo de la Revolución rusa- que para el análisis traduce en el terreno fáctico la doble contradicción presente: una de índole inter-imperialista o colisión de las distintas potencias imperiales, la otra de esencia clasista, de lucha de clases en el sentido marxista.
Al inicio prevaleció el primer eje de la contradicción inter-imperialista. La confrontación bélica se desencadena ante la impotencia para evitarla de los revolucionarios. Pero en el marco de la misma surge la coyuntura que propicia y vuelve posible, por primera vez en la historia, el triunfo de la Revolución socialista. En un país atrasado lejano del desarrollo capitalista de otras naciones.

\section{La Revolución rusa no es una, sino que son dos}

En efecto, no puede entenderse a cabalidad la Revolución soviética de
1917, sin entrar a analizar su antecedente inmediato: la revolución 
de 1905. La necesidad de ligar el acontecimiento con lo que tiene de proceso nos conduce a encontrar en él dos momentos de auge revolucionario, dos revoluciones en una. La primera, pacífica, moderada, dirigida por sectores atrasados políticamente, movilizó a la muchedumbre a solicitarle al zar, el "padrecito" de todos los rusos, que intercediera ante sus ministros y ante la policía, que por favor frenara la represión.

La Revolución rusa debe ser analizada como proceso. No es sólo un momento, un punto, sino que es una línea que se nos alarga. 0 más bien, ambas cosas a la vez. Valga el ejemplo: al igual que todos tenemos nuestra fecha exacta de nacimiento - día, mes y año- también así la tiene la revolución triunfante. Sabemos, sin embargo, que esa fecha de nuestro cumpleaños indica falsamente desde cuándo estamos por aquí. Venimos de un proceso de gestación (en la barriga de nuestra mamá) que se prolongó por varios meses, y del que no sabríamos dar el dato exacto de inicio. Pues en forma similar podemos referirnos a la Revolución rusa. Tendrá su aniversario como todos nosotros pero venía siendo incubada - se estaba gestando-desde mucho antes.

\section{La revolución "pacífica” de 1905 se cobró más vidas que la insurrección violenta de 1917}

La gente en 1905 esperaba la ayuda del emperador ruso para saciar su hambre, poner fin a la guerra con Japón y cesar el reclutamiento militar y la represión. Pero la guardia cargó, a caballo y sable en mano, contra los manifestantes, mientras los soldados de palacio dispararon sobre la multitud. Una serie de huelgas y protestas se sucedieron el resto de ese año y a lo largo de 1906, hasta que el movimiento popular, agotado por la represión y los encarcelamientos, se desactivó.

Sin embargo, la revolución de 1905 no fue en vano. Muchas lecciones fueron aprendidas. $\mathrm{El}$ pueblo ya no volvería a confiar en el supuesto paternalismo del zar. Pudo comprobar que el problema no eran sus ministros o funcionarios: el problema era el propio sistema zarista.

Las peticiones pacifistas y los líderes moderados ya no volverían a arrastrar a nadie. Fue la propia dictadura zarista la que educó al pueblo en la violencia. Serían en adelante los líderes más radicales y agresivos, quienes serían seguidos. De entre ellos destacan los inspirados en las ideas de Marx: la socialdemocracia rusa, fueron protagonistas de los hechos revolucionarios de 1917. ¿De dónde vienen? Eso nos remite un poco más atrás. 


\section{El II Congreso del POSDR fue en realidad el primero, el fundacional}

Allá por 1898 , marxistas procedentes de distintas regiones rusas se reunieron para fundar el Partido Obrero Social-Demócrata Ruso, POSDR. A las pocas semanas, la policía zarista los había apresado a todos. La totalidad del Comité Central electo en ese primer Congreso resultó encarcelado antes de haber creado una red organizativa o una estructura de partido. Del POSDR solamente quedaban las siglas y la memoria: alguna vez intentó crearse en la Rusia del zar un partido inspirado en el marxismo, un partido revolucionario. Era un recuerdo importante, un esbozo o primer intento de algo, todavía no existente realmente.
Así lo consideraron una serie de intelectuales y líderes del movimiento obrero y campesino ruso que por distintas circunstancias habían tenido que salir huyendo y vivían en el exilio, en diferentes países europeos. En consecuencia, decidieron dos cosas: convocar a un congreso fundacional a realizarse en el extranjero, donde la represión zarista no pudiera llegar, para asegurar al menos el inicio de un proceso organizativo al interior del país; y, en segundo lugar, conservar el nombre POSDR y llamarlo II Congreso, en memoria y reconocimiento de los protagonistas del intento anterior. Éste fue realizado en Londres en 1903.

\section{Los marxistas rusos queriendo fundar un partido, en realidad crearon dos}

Desde el inicio del II Congreso resultó claro que había dos posturas enfrentadas. Todos coincidían en el marxismo como su fundamento teórico y político. Es decir, coincidían en la idea de que hacía falta una revolución proletaria que, tomando el poder, emprendiera las tareas de construcción del socialismo. Tampoco se debatió mayormente sobre si había condiciones para tal revolución, pues a todos les parecía evidente que no; Rusia estaba sumida aún en el feudalismo, apenas daba inicio a su Revolución industrial y la revolución pendiente era, por eso mismo, la revolución democrático-burguesa.

A los marxistas les correspondería acompañar tal proceso histórico, esperar que se consumara el arribo de la burguesía al poder, el desmontaje de la dictadura feudal del zarismo, el inicio de la democratización y del despliegue del capitalismo en Rusia. Su papel debía quedar reducido a participar y tratar de acelerar ese proceso. A la vez, prepararse y preparar a las 
masas para las futuras batallas por el socialismo, las que no podrían emprenderse sino culminada esa fase previa.

Pero, habiendo unanimidad a grandes rasgos en el objetivo y en la misión histórica, la discusión se centró en cómo debía estar organizado el partido. ¿Cómo asegurarse de que la policía no volviera a desbaratarlo? Habría evidentemente que extremar las medidas de seguridad, la clandestinidad, el trabajo conspirativo, pero ¿no aislaría eso al partido de las grandes masas de trabajadores? ¿No haría eso imposible la labor de conciencia, organización y movilización? Por otra parte, ¿qué tanta disciplina debía haber en su interior? ¿Cómo asegurar la discusión y a la vez la unidad?

\section{El nombre menchevique significa la minoría, mientras con la palabra bolchevique se indicaba la mayoría. Sin embargo, desde entonces en adelante fueron los mencheviques mayoritarios, mientras la minoría fue bolchevique}

El debate por la concepción organizativa dividió a los participantes en el Congreso. El partido nacía realmente partido. Se habían formado dos bandos. Pléjanov, viejo marxista respetado por todos porque había conocido a Marx personalmente y traducido algunas de sus obras al ruso, no pudo conciliarlos. De un lado, Martov y un grupo insistían en el respeto democrático al criterio de cada uno que de forma voluntaria se adhería a la revolución y al partido. Éste debía -en su opinión- estar abierto a la participación masiva de todos los trabajadores que estuvieran de acuerdo con los ideales que proclamaba el POSDR.

Del otro lado, un fogoso orador de calva precoz y apellido Ulianov, de nombre Vladimir Illich, pero al que todos conocían por el seudónimo de sus escritos: Lenin. La contundencia de sus argumentos y la fuerza de sus palabras hicieron inclinarse la mayoría a su favor. Incluso Pléjanov lo terminó respaldando. Nacía así la fracción "bolchevique", mientras los partidarios de Martov resultaban bautizados como "mencheviques".

Lenin defendió como prioritarias las cuestiones de seguridad y la necesidad de construir una organización unida sólidamente, que no se paralizara por discusiones interminables -que tan frecuentes eran en el exilio ruso- sino basada en la "unidad de acción". Concebía un partido "de nuevo tipo", que educara a las masas y las guiara, que fuera "vanguardia" de ellas. Ese partido sería "de masas" sólo por representar sus intereses históricos, pero por su 
composición debía ser un partido "de cuadros". Sólo aquellos revolucionarios más experimentados, los más probados y capaces, debían adquirir la calidad de miembros. Serían "profesionales de la revolución", con una vida de total clandestinidad, y capaces de soportar la cárcel o las torturas sin dar información a la policía política del zar. Era una concepción casi militar de organización partidaria coherente con la idea insurreccional que Lenin se había formado de cómo debería ser la revolución.

\section{Lenin fue expulsado utilizando sus propios argumentos}

El II Congreso dejó constituido un Comité Central donde los mencheviques eran lógicamente minoría, pero Lenin no estaba satisfecho. En la redacción del periódico del partido también había representación de los mencheviques. Exigió su expulsión. El periódico no debía promover dos líneas políticas sino una sola: la de la mayoría. "Si no se van ellos, me voy yo".
Parecía muy poco razonable, los mencheviques acusaron a Lenin de ambicioso. Muchos de sus partidarios lo abandonaron, también Pléjanov. Mayoritarios ahora, los mencheviques sacaron a Lenin y su grupo del diario. Éstos crearon otro. Él ya no llegó más a las reuniones del Comité Central; los bolcheviques crearon el suyo propio. La escisión estaba consumada.

\section{Lenin no siempre fue leninista}

Claro -puede pensar alguien- de niño no era todavía leninista. No es eso. Tampoco que durante su proceso de formación política haya habido un período en el que "todavía" no había desarrollado a plenitud su pensamiento y no se le pueda considerar leninista; No. La frase hace referencia a algo realmente paradójico: Lenin "dejó de ser" leninista en coyunturas concretas. Eso lo llevó a chocar con muchos de sus partidarios, plenamente "leninistas", que esgrimían ahora contra él sus propios argumentos del pasado.
El exagerado verticalismo y la restricción al ingreso eran para Lenin condiciones impuestas por la situación de persecución y acoso a que estaban sometidos los revolucionarios. Pero en períodos de auge de la lucha, de grandes movilizaciones y movimientos huelguísticos, Lenin insistió en "abrir" el partido $y$ en democratizar sus estructuras. Fue el caso de los años 19051906. Propugnó el derecho de las bases a elegir y a poder remover a sus dirigentes. Incluso defendió que en las asambleas de partido 
participasen, con derecho a voz y voto, obreros que no eran miembros del mismo. Impulsó la reconciliación con los mencheviques. En 1906 por su impulso se realizó en Londres un Congreso de reunificación. Su concepción era democratizar en los momentos de ascenso revolucionario. Con el reflujo de masas que sobrevino a partir de 1907, Lenin endureció de nuevo su postura y los bolcheviques retornaron a su rigor militante.

\section{No siempre el contexto internacional es factor externo, a veces juega como factor interno}

Resulta decisivo para el éxito de una revolución "nacional" ese elemento "externo". Al menos era la concepción de los bolcheviques, aparentemente confirmada por la experiencia rusa. Las condiciones para la revolución de masas - la que caracterizó Lenin como "situación revolucionaria”- llegó de la mano de la situación internacional: el estallido de la Primera Guerra Mundial y la participación en ella de la Rusia zarista.

No en todos los países participantes se generarían condiciones revolucionarias, pero en el caso de Rusia confluía el atraso económico con la dureza de la dictadura. La guerra agudizó y volvió insoportables las ya durísimas condiciones de vida del pueblo ruso. Las contradicciones se agudizaban, incluida la que enfrentaba a la incipiente burguesía de ideología liberal y antifeudal, con la tradicional nobleza terrateniente representada por el zarismo. El régimen no había podido resolverla y ahora, en las dificultades de una guerra desfavorable para su ejército imperial, perdió control de la situación. La habilidad de Lenin y su genio de estratega hallarán en la situación una coyuntura excepcionalmente favorable para impulsar y llevar al poder una revolución de signo proletario.

\section{La revolución de 1917 no fue una, fueron dos}

O sea, la de febrero y la de octubre. Nuevamente, nos encontramos dos momentos en un solo proceso. De nuevo, la primera no será bautizada como la "de febrero", sino hasta cuando se da la segunda. Inicialmente se le llamó "revolución de 1917". Ésta, aunque más moderada que la de octubre, ha sido verdadera revolución. Derribó el gobierno, expulsó al zar y destruyó la dictadura. El movimiento era amplio y en él confluían sectores populares con terratenientes medianos, burguesía 
industrial, capas medias. Es la revolución democrático-burguesa que todos habían esperado. Organizó un "gobierno provisional" y colocó a un liberal al frente: Kerensky.

\section{Ser demasiado débil puede ser una ventaja}

¿Cómo hizo Suiza, situada geográficamente en medio del continente en llamas, para librarse del incendio de la guerra? Simplemente, no hacer nada. $O$ sea, mantener abiertos sus bancos. Mantener, desde luego, el secreto bancario. Dejar abierta la posibilidad a todos -Estados 0 personas particulares, empresarios, ministros o militares- de ir hasta ahí y abrir sus cuentas. Sin hacer preguntas. Total confidencialidad. La procedencia o la nacionalidad no importan. El dinero no tiene patria.

Por lo mismo, el país con mayor concentración bancaria en Europa no podía tener otra política más que la neutralidad. Ésta fue aceptada y respetada por todos. ¿A quién le iba a interesar hacer la guerra, bombardear o invadir el lugar donde se guardaban sus tesoros? La habilidad suiza contemporánea en explotar su imagen pacífica y humanitaria contrasta con su igual habilidad para dar cobijo al tráfico de armas o a corruptos de todo tipo. 0 con sus tradiciones medievales. Por siglos, todos los ejércitos del continente tenían mercenarios de la pobre y belicosa Suiza; todavía ahora el Vaticano mantiene el anacronismo de la Guardia Suiza como un cuerpo especial de protección al Papa.

Un territorio cuya neutralidad es respetada por todos tiene otra ventaja: es el lugar óptimo para buscar información. Espías de todas las nacionalidades y al servicio de todas las potencias se hacían ahí presentes, se mezclaban con miembros del servicio diplomático, con hombres de negocio, gente acomodada gozando de sus vacaciones o esperando que la guerra terminara... Conspiraciones de todo tipo se entremezclaban en ese pequeño y excepcional país.

También había revolucionarios de todas las nacionalidades que en Suiza encontraban el mejor lugar para su exilio. De entre ellos, desapercibido en medio de esa gran confusión, un hombre menudo y de calva brillante, de ojos pequeños pero penetrantes: Lenin, quien lograría atravesar media Europa, en marzo de 1917, en mitad de la guerra, escondido en un vagón sellado, hasta ingresar a Rusia desde Finlandia. Se ha especulado si tal hazaña no sería por la complicidad del servicio secreto alemán, 
en guerra con Rusia, y por ello interesado en que el agitador llegara a complicar aún más las cosas al interior del Estado ruso. El rumor nunca se pudo comprobar pero tampoco suena improbable; sería otra prueba más de la audacia de Lenin en utilizar todo al servicio de su causa.

\section{3. ¿Derribar al gobierno surgido de la revolución para salvar la revolución?}

En la capital, a principios de abril, se esperaba con expectación la llegada de Lenin, el ya legendario líder de los bolcheviques. Éstos habían participado activamente en las jornadas revolucionarias de febrero y, lógicamente, apoyaban al gobierno de Kerensky organizado desde ellas. Por eso sorprendió a los propios camaradas la radical posición que asumió Lenin. En un incendiario discurso en la plaza abarrotada, denunció la timidez de la burguesía para terminar con el aparato estatal del zarismo, su incapacidad para poner fin a la guerra y su ineptitud para dar respuesta satisfactoria a las demandas populares. Proclamó que la etapa democrático-burguesa de la revolución quedaba superada, que sólo la alianza de los campesinos con los obreros podía salvarla y señaló que la revolución pendiente era socialista. Al gobierno liberal-burgués lo conminó a entregar el poder a las comisiones de delegados elegidos en asambleas: "iTodo el poder a los soviets!" Todos, incluidos los de su propio partido, quedaron estupefactos.

\section{El líder más conocido y popular del partido bolchevique, en realidad no era bolchevique}

$\mathrm{Ni}$ los mismos bolcheviques entendían qué se proponía Lenin. Sus posiciones de ahora contradecían las de los años precedentes. Además, sus argumentos se parecían mucho a los que el menchevique Trotsky había enunciado tiempo atrás y que Lenin rechazaba. Su coincidencia actual era un hecho. En realidad, Trotsky estaba cerca de los bolcheviques en casi todo, excepto por su reclamo de democracia interna. Por esa razón, en el II Congreso respaldó a Martov y se opuso a Lenin, pero estaba en disgusto con los mencheviques, donde imperaba la moderación. La revolución de 1905-1906 le dio la oportunidad de demostrar su valor y su capacidad organizativa; se sumergió de lleno en las asambleas de trabajadores, en la organización de los soviets. 
En plena efervescencia revolucionaria fue electo jefe del soviet de Petrogrado, la capital. Desde ahí dirigió la cadena de huelgas y protestas de 1905 y parte de 1906. Terminó encarcelado y desterrado a Siberia. Aprovechó ese tiempo para redactar un análisis. Su conclusión era que en Rusia la burguesía era débil, indecisa y conservadora: contar con ella para la revolución era un error. Había que sobrepasarla.

Ahora que Lenin compartía su visión sobre la actualidad y la posibilidad de la revolución proletaria socialista, Trotsky pactó su ingreso al partido bolchevique. Sería admitido e incorporado al Comité Central. No todos vieron bien ese ingreso "por arriba", algunos recelaban del antiguo adversario. Pero no ingresaba solo: miles lo siguieron y se pasaron con los bolcheviques. Además, a éstos les interesaba el carisma de Trotsky -ampliamente conocido como el héroe de la insurrección de 1905- y también su talento organizativo. Así pues, Lenin logró su incorporación; Trotsky no lo iba a defraudar.

\section{El Buró Político se creó para la insurrección. Sin embargo, incluyó a dirigentes que habían estado contra tal decisión}

En un período revolucionario como era aquél, la situación evoluciona muy rápido. El gobierno burgués de Kerensky no lograba organizar ni la producción ni la distribución. Escaseaba todo. A las protestas populares respondía con represión cada vez más intensa, mientras en los frentes militares la situación se volvía insoportable. Los bolcheviques se agitaban contra el gobierno y su influencia crecía. Ahora tenían una presencia grande en los soviets de obreros, de soldados y de campesinos. Trotsky, su antiguo líder, estaba ahora encargado por los bolcheviques para esa tarea. Cuando se acercó octubre, Lenin analizó que el momento para la insurrección estaba próximo. Pero varios en el
Comité Central se oponían. Unos pedían más tiempo, otros estaban francamente en contra de tomar el poder en las difíciles condiciones que había en el país. Finalmente, se conformó una pequeña comisión de sólo siete miembros que pudiera reunirse a diario y dirigir en detalle la insurrección. Zinoviev y Kamenev entraron en ese organismo aun después de haberse opuesto a los argumentos de Lenin, pero éste consideró que en la Comisión Política debían estar los dirigentes más capaces. Una vez tomada la decisión por mayoría simple, la democracia estaba en que todos la respetaran y trabajaran por ella, aun estando en desacuerdo. 


\section{La Revolución de octubre en realidad se hizo en noviembre}

La idea de Lenin era aprovechar la convocatoria del Congreso de Soviets de toda Rusia para que fuera éste el que decidiera hacer el llamado a la nación. También quería adelantarse a la elección de diputados. En la concepción de Lenin, los soviets eran un poder paralelo que debía sustituir al parlamento burgués. El partido se lanzó a una gran labor de agitación y organización, tanto en las fábricas como también en los cuarteles. La adhesión de oficiales y muchos soldados al levantamiento neutralizó otros cuarteles y provocó la rendición de la policía. Hubo poco combate y la toma del poder fue rápida. La fecha clave fue el 25 de octubre, pero años más tarde hubo un reajuste del calendario. Rusia pasó del calendario juliano al gregoriano, pues había un desfase con el calendario astronómico. El aniversario de la gesta revolucionaria se celebraría desde entonces el 6 de noviembre.

\section{Una revolución con muchos nombres}

Se la conoce como la "Revolución rusa", pero es también -como hemos visto- la "revolución de 1917", para no confundirla con la de 1905 . No solamente, asimismo se le llama la "Revolución de octubre" a fin de distinguirla de la de febrero del mismo año. Es la "Revolución bolchevique" por el partido que la desencadenó y dirigió. Por otra parte, es la "Revolución soviética" dado el papel de los soviets -a los que debería habérseles dado el poder siendo fiel a la consigna bolchevique - así como es la "Revolución comunista" por excelencia. No debería haber sido tomada como un modelo a imitar y repetir, el propio Lenin insistía en ello, consciente de las condiciones totalmente excepcionales en que se había logrado el triunfo. Lo difícil no había sido en realidad tomar el poder, lo verdaderamente difícil iba a ser defenderlo y conservarlo, peor aún: ¿cómo usarlo para avanzar hacia el socialismo?

\section{Una revolución marxista contra las tesis de Marx}

Gramsci lo resumió en un artículo de título expresivo: "La revolución contra El Capital”. ¿Cómo una revolución que no fuera mundial podía ser socialista? Además, ¿socialismo en un país atrasado, pre-capitalista como era Rusia? Parecía contradecir al fundador del marxismo. Sin 
embargo, la Revolución rusa era un hecho. 0 bien se la criticaba, o bien se solidarizaba uno con ella. Al respecto, la socialdemocracia se dividió. La mayoría reformista condenó la "aventura" bolche- vique. La minoría revolucionaria al contrario respaldó a Lenin. Pronto adoptarían el nombre de "comunista". Nacía así la Tercera Internacional, conocida también como Komintern o Internacional Comunista.

\section{9. ¿Debía sacrificarse la revolución nacional para salvar la revolución mundial? ¿O salvar la primera aun a costa de la segunda?}

Sobre el papel, en lo teórico, no se veía contradicción entre revolución nacional y mundial. Los bolcheviques concebían su revolución como parte de un proceso mundial, pero la realidad práctica los colocó ante una disyuntiva concreta: ¿Debían firmar la paz con Alemania? No hacerlo significaba defraudar a las masas en un punto sensible; además había sido una de las promesas centrales del lema con que se agitó para la insurrección: ¡Paz, pan, tierra, libertad! Pero hacerlo significaba regalarle un respiro militar y político al régimen alemán y truncar la posibilidad de una revolución en Alemania. Traería también el costo de las represalias aliadas, ya que se había convenido que nadie firmara una paz por separado, se consideraría equivalente a una traición. Pero, por otra parte, la situación del ejército ruso era desesperada, sin abastecimientos y con deserciones masivas.

Lenin insistía en firmar la paz; a cualquier costo. Para así ganar un tiempo precioso en organizar la defensa, pero casi toda la dirección del partido estaba en contra. Semanas más tarde, la situación era tan crítica que aceptarían la estrategia de Lenin. Alemania con la paz de Brest-Litovsk obtenía casi todas sus pretensiones. Rusia perdía el control de Finlandia, Estonia, Letonia, Lituania, Polonia y parte de Ucrania, pero la revolución ganaba un respiro. Al jefe de la diplomacia soviética, León Trotsky, se le encargóorganizar el Ejército Rojo. La Revolución rusa lograba cumplir su primer aniversario mínimamente consolidada, pero en Alemania el intento insurreccional del partido comunista alemán (recién fundado por Karl Liebknecht y Rosa Luxemburgo) era aislado y reprimido. Se salvó la revolución que estaba en el poder y que era real; pero se frustró la otra, la que era sólo posibilidad. Se había impuesto el realismo de Lenin, pero la revolución sobrevivía aislada. 


\section{Un chiste le costó la vida}

Sin revolución mundial había que levantar la moral del pueblo, prepararlo para una resistencia larga, recordar sus tradiciones de lucha, apelar a su orgullo: la suya era la primera revolución socialista triunfante. Alguien propuso la consigna: "construir el socialismo en un solo país". Lenin lo aprobó como simple lema propagandístico. Stalin parecía tomárselo en serio. Zinoviev no pudo resistir la tentación de burlarse un poco: "Claro, ¿por qué no? Empecemos construyendo socialismo en una sola ciudad. Y después socialismo en una sola calle". Las risas eran inevitables. Para aquellos viejos veteranos del marxismo, la idea de que en un solo país pudiera ser levantado el socialismo era claramente absurda y contraria a las ideas marxistas. El único que no reía era Stalin, hombre poco instruido pero práctico, él era quien controlaba el Comité de Organización, tenía ya mucho poder, pronto tendría más, y el poder no admite bromas: odia el humor. Años después, Zinoviev lo entendería -ya muy tarde- frente al pelotón de fusilamiento.

\section{El "pecado original” del sectarismo o cómo la mayoría fácil puede volverse minoritaria}

Tras el fracaso de la revolución alemana se concluyó que la prioridad era salvar la Rusia bolchevique "patria de los trabajadores del mundo". Se acentuaban hacia el interior las tendencias nacionalistas. Hacia el exterior tendían a supeditarse las políticas de los revolucionarios de los demás países a las prioridades rusas. Esto incidió en la política de la III Internacional. Pero el peor lastre era el sectarismo con que nacía dicha organización. La lista de condiciones para que un partido fuera aceptado incluía romper con la II Internacional -a la que se acusaba de reformista- y la expulsión de los socialdemócratas de sus propias filas. Esto provocó la escisión en muchos partidos donde no había una razón para ello. No en todos los partidos marxistas la situación interna era desgarrada como lo fuera entre mencheviques y bolcheviques. Se hubiera podido mantener la unidad y la fuerza que la unidad supone.

Un caso paradigmático fue el del Partido Socialista Obrero Español (PSOE): la mayoría de sus militantes simpatizaba con los bolcheviques y apoyaba las tesis de Lenin, pero una parte no veía bien tener que retirar a su partido de la II Internacional, pues eso era regalársela a la tendencia reformista. Otros sí aceptaban salir de una Internacional para entrar a la 
otra, pero rechazaban la imposición de expulsar a la minoría reformista de sus propias filas. De tal modo, en las votaciones internas, la que era mayoría revolucionaria se redujo finalmente y quedó en una minoría. Se separaron del PSOE para fundar el Partido Comunista de España (PCE). Así se repetiría la historia en otros países. Se creaban los distintos PC, pero siempre minoritarios y afectados de este sectarismo que los acompañaría en su vida como su propio "pecado original".

\section{Cuando un "exceso" de democracia de hecho la destruye}

Ya en Lenin era notoria la tendencia sectaria y ultrarradical. En Stalin esto mismo se presentaba exagerado, no era hombre especialmente inteligente, pero era astuto, y lo peor: ambicioso, cruel y sin escrúpulos. Ideó una estratagema para conseguir la mayoría al interior del partido: "democratizarlo". Abrió las puertas a la afiliación masiva. Su excusa era que creciendo, el partido se iba a fortalecer. El país era inmenso y los bolcheviques muy pocos.

Estando el partido en el poder, tener el carnet de militante signifi- caba acceso a lo que el poder puede conseguir. Muchos de los nuevos militantes no eran más que arribistas que fingían un lenguaje revolucionario. Otros tal vez se afiliaban de buena fe pero, faltos de experiencia, permanecían leales a Stalin. Al fin y al cabo, éste había bregado por obtener su incorporación. En pocos meses los comunistas con largos años de militancia clandestina, la vieja guardia bolchevique, eran minoría dentro de su propio partido; Stalin triunfaba "democráticamente".

\section{Quien masacró a los comunistas rusos fue el propio Partido Comunista}

La intolerancia era posiblemente un rasgo de Lenin; en Stalin adoptaría formas sanguinarias. Con Lenin no había decisión que no fuera precedida de una larga y profunda discusión. Los que salían derrotados en ella debían someterse al acuerdo mayoritario pero eran respetados. Incluso se les permitía insistir y volver a exponer públi- camente sus puntos de vista. Con Stalin quien perdía el debate podía también perder la vida. En sucesivos momentos se enjuició y fueron condenados a muerte todos y cada uno de los grandes dirigentes de la Revolución de octubre. Asimismo, muchos de los militantes de base, héroes de muchos años, eran ahora injustamente acusados de traición 
sólo por no estar de acuerdo con las directrices de Stalin.

El estalinismo fusionó totalmente el partido con el Estado. El partido se llenó de burócratas y de oportunistas; al mismo tiempo eran purgados los verdaderos revolucionarios. Se repetía la mitología de Cronos, el dios griego que devora a sus hijos: la revolución devoraba asimismo a sus propios hijos.

\section{Trotsky fue víctima de su propia profecía}

Se cumplía ahora, casi al pie de la letra, algo que Trotsky había advertido muchos años antes, cuando en el debate de 1903 se opuso a la concepción leninista de partido. "El aparato de organización sustituirá al partido, el Comité Central reemplazará al aparato y finalmente el Secretario General, como un verdadero dictador, sustituirá al Comité Central". Sólo faltaba algo que no existía antes: el Buró Político. Éste se había vuelto permanente y en lugar de rendirle cuentas al Comité Central de hecho lo reemplazaba como órgano máximo de decisión. En los Congresos, la militancia elegía al Comité Central pero ya no era en realidad la instancia máxima, sino que lo era la Comisión Política.

Trotsky denunció con toda firmeza la acumulación de poderes por parte de Stalin, su manipulación, sus métodos criminales. Todo en vano. Stalin lo acusaba de haber sido menchevique hasta 1917 , opuesto a Lenin, de no ser verdadero bolchevique, de seguir siendo menchevique. El héroe de 1905-1906, el dirigente de los soviets en la Revolución de octubre, el jefe de la diplomacia soviética en la difícil negociación de Brest-Litovsk, el organizador del Ejército Rojo, ¿un contrarrevolucionario? Él denunciaba que, lejos de estar construyendo la dictadura del proletariado, Stalin estaba levantando una dictadura clásica y convirtiéndose en el nuevo zar. Pero estos eran más argumentos para acusar de enemigo a Trotsky.

Fue expulsado del Comité Central, poco más tarde del partido, finalmente también del país; marchó exiliado a México. Caería brutalmente asesinado por un agente de Stalin. El socialismo en su versión estalinista demostraba ser capaz -también él- de atrocidades nunca vistas.

\section{La realidad de los vínculos económicos se impone frente a los sentimientos y los resentimientos}

En Versalles redactaron el Tratado de Paz los líderes de las 
Francia y Wilson por los Estados Unidos. Éste último se mostró conciliador y lo mismo el primer ministro británico, pero el jefe del Estado francés se puso bien intransigente. El ejército alemán debía empequeñecerse a tamaño simbólico (sólo 100 mil hombres). Francia exigía también de Alemania el pago de reparaciones de guerra: por toda la infraestructura dañada, más el costo de hospitalización de los heridos, las pensiones anuales a los lisiados de guerra y a las viudas de los caídos. Era un monto extremadamente elevado; se calculó en 35 mil millones de dólares. Alemania no estaba en condiciones de pagar tanto. Las medidas tan drásticas hundían la economía germana y no le permitían a Alemania recuperarse. Ante los retrasos en los pagos germanos, los franceses ocuparon la cuenca del Ruhr, zona rica en carbón y considerada el corazón industrial de Europa.

\section{Cuando la paz se constituye en el preludio de la guerra}

Al fin los franceses tuvieron que ceder, retirarse de la cuenca del Ruhr y aceptar flexibilizar el cumplimiento de las cláusulas de Versalles: la crisis alemana afectaba a toda Europa y a la propia Francia. Las economías del continente europeo estaban entrelazadas, a tal punto que ya no era posible tratar de hundir una de ellas sin resultar uno mismo salpicado por la oleada de recesión. El revanchismo del francés Clemenceau no era realista, pero la actitud de venganza, aunque inútil en los hechos, no dejaba de tener serias consecuencias: un gran resentimiento en la nación alemana.

Bismarck había sometido a Francia en 1871 al pago de repa- raciones de guerra, por lo que ésta no estaba sino repitiendo, ahora a una escala mayor (Francia consiguió cancelar su deuda en sólo tres años), el mismo trato que había recibido el siglo anterior de sus viejos enemigos. Esa implacable lógica resultaba inaceptable para Alemania, humillada y resentida, buscaría en el rompimiento unilateral de las cláusulas de Versalles y en el rearme la hora de su revancha. La poderosa Alemania iba pronto a reincidir en el clima belicista. Lejos de consolidar y extender la democracia, lo que terminaría favoreciéndose era el surgimiento de fuerzas ultranacionalistas y antidemocráticas: el Tratado de Versalles sirvió para incubar los terribles fascismos. 


\section{A veces, los ideales del idealismo traen consecuencias negativas}

El presidente estadounidense ya venía filosofando desde antes de que -en 1917- Estados Unidos entrara en la guerra europea. Wodroow Wilson había planteado, sin que ninguno de los contendientes le hiciera mayor caso, la idea de "una paz sin victoria". También retó a los estadistas de los países beligerantes que dieran a conocer los objetivos que habían tenido al momento de iniciarse la contienda para explorar diferentes formas de obtenerlos. Después elaboró una propuesta de 14 puntos para configurar un escenario post-bélico que garantizase una paz estable y duradera. La idea central era la creación de una Sociedad de Naciones donde participasen todos los países y sirviera para resolver las controversias, evitando nuevas situaciones de confrontación.
Con base en dicha propuesta fue que Alemania aceptó, el 11 de noviembre de 1918, el armisticio. Tras cuatro años de contienda, 10 millones de muertos y el doble de heridos, las potencias centrales habían sido vencidas y aceptaban su derrota confiadas en que las condiciones serían basadas en la propuesta de Wilson. Esta expectativa resultó frustrada, pues ni los británicos ni -sobre todo- los franceses compartían la generosa visión del estadista norteamericano, por el contrario: imponían duras condiciones a los vencidos. El propio Wilson resultó chasqueado cuando el Congreso de su propio país rechazó adherirse a la Sociedad de Naciones. Ésta nacía sin la participación de la potencia que la había propuesto e impulsado. Era todo un fiasco.

\section{Ignorando que estaban viviendo el "período de entreguerras" llamaron "felices veinte" a esos primeros años de posguerra}

Terminada la carnicería de la Gran Guerra, quienes habían sobrevivido experimentaban la alegría de vivir y el optimismo ante el futuro. Una buena parte de Europa estaba devastada y debía ser reconstruida con grandes sacrificios, pero por lo menos esto suponía que había trabajo y una esperanza en el hori- zonte. En Estados Unidos era mejor, pues la contienda se había desarrollado lejos de su territorio: allí no había caído una sola bomba, ni había llegado siquiera una bala perdida. El esfuerzo de guerra había producido una situación de pleno empleo, había trabajo y circulaba el dinero. Empezó a darse mucha 
vida nocturna: abrían más y más locales con música, baile, alcohol. Pero pronto, sectores conservadores legislaron con la sana intención de preservar los valores morales y acabar con tal desenfreno.
Aprobaron un decreto que prohibía la producción, venta y consumo de bebidas alcohólicas. La población, irónicamente, la bautizó con el apelativo de "Ley Seca".

\section{La Ley Seca, en vez de promover la virtud favoreció el vicio y fortaleció a la mafia}

La naturaleza humana tiende a rebelarse frente a las prohibiciones, como ejemplifica la Biblia al referirse a la primera pareja humana en el paraíso: era sólo cuestión de tiempo para que acabaran probando el fruto prohibido. Desde que estaba perseguido, con más avidez el público buscaba la manera de burlar la prohibición y encontrar dónde poder consumir alcohol. La ley conseguía el efecto contrario al objetivo buscado. Además, convertía en infractora a una buena parte de la población, tratada como delincuente, mientras los verdaderos delincuentes se favorecían al ser los únicos dedicados a la producción clandestina o al contrabando desde Canadá. Grupos del hampa se enriquecieron durante la vigencia de la Ley Seca, convirtiendo a las diferentes mafias en un verdadero poder económico.

\section{La hiperinflación hace que la sensatez resulte insensata, premia la insensatez e invierte los valores}

Alemania, grandemente destruida y sometida a la presión desmesurada del pago de las reparaciones de guerra, cayó en una tremenda hiperinflación de varios dígitos. La clase media fue la más afectada. Efectivamente, el valor de los ahorros se desvanecía, viejas inversiones en inmuebles para alquilar resultaban ruinosas, la conducta previsora y prudente era castigada por la inmisericorde subversión de la crisis inflacionaria. Por el contrario, quien nunca se había preocupado por hacerse con una vivienda propia resultaba favorecido desde el momento en que el valor de los alquileres se derrumbaba hasta montos ridículos. Lo irracional de la dramática devaluación de la moneda volvía como la más racional conducta de vivir al día, gastar inmediatamente el salario, dado que su poder adquisitivo se derrumbaba en cuestión de días y era imprevisible saber qué se podría comprar con él en la siguiente semana. Derrochar o gastar en diversiones y alcohol, 
pues el nihilismo imperaba y se imponía apurar el presente ya que el mañana es pura incertidumbre.
Los "felices veinte" tienen ese toque negativo y nihilista en la Europa de posguerra.

\section{El período de entreguerras (1919-1939) se divide en dos mitades contrapuestas: la crisis de 1929 abrió paso a "la Gran Depresión" que viene a ser la negación de "los felices veinte”}

La forma como se vivió la década de los veinte cargaba con mucho artificio, lo cual se puso brutalmente de manifiesto cuando sobrevino la terrible crisis económica de 1929. El aterrizaje en la realidad fue duro e inesperado. Especialmente en Estados Unidos, donde dio inicio esa crisis estructural del sistema capitalista, la más grave desde mediados del siglo XIX. Arrancó como una crisis bursátil, el famoso "Crac de la bolsa" de Nueva York, pero tras ella hizo crisis la economía real, denotando que se trataba de una crisis de sobreproducción, muy propia del sistema capitalista, que de forma repetida y cíclica se produce a nivel mundial. Por tener causas múltiples y derivar en diversas manifestaciones es de difícil solución y de hecho se prolongó al resto de la década. Algunas estrategias económicas lograron atenuarla pero su superación no se dio sino con el comienzo de la Segunda Guerra Mundial. La violencia de la guerra -como en su momento señalara Hegel- se mostraba como la única capaz de imponerse sobre la violencia de la vida económica.

\section{Se le llama Crac del 29 porque la Bolsa se quebró como una rama seca al partirse}

La burbuja especulativa venía hinchándose desde hacía varios años. El comportamiento insensato de los bancos acentuó el fenómeno: los préstamos bancarios a corredores, que eran de 2 mil 707 millones de dólares en mayo de 1926, se había disparado a 8 mil 549 millones en septiembre de 1929. El continuo ascenso del valor de los títulos movió también a muchas personas a invertir sus ahorros en la Bolsa. Un millón y medio de especuladores se vieron sorprendidos por el cambio abrupto de tendencia. El movimiento a la baja empezó el martes, siguió el miércoles y culminó el jueves 22 de octubre de 1929. Sólo en ese día, llamado "jueves negro", se vendieron 13 millones de acciones. Peor todavía fue el "martes negro", 29 de octubre, cuando 
fueron 16 millones y medio de acciones las que se pusieron a la venta. A fines del año, el valor de las mismas había caído un 50\% y arrastró en su desplome a bancos y empresas.

\section{Cuando todo el mundo se vuelve loco, lo único cuerdo es volverse loco también}

$Y$ es que en un fenómeno aparentemente de índole económica, pero donde la confianza cuenta mucho, la dimensión psicológica resulta importante. Se originó una reacción de pánico. Todo el mundo, repentinamente, quería vender. Nadie quería comprar. $\mathrm{Y}$, por ende, el desplome en la cotización de las acciones era inevitable. Se volvió más catastrófico por la reacción de pánico de los dueños de títulos valores. Es semejante a un siniestro en una discoteca: que se haya iniciado un incendio tal vez no hubiera sido tan catastrófico, si no fuera por los gritos -ifuego, fuego!- que provocaron una estampida entre la gente haciendo que muchas personas fueran aplastadas por otras que pugnaban por salir atropelladamente. En una situación extrema como la descrita no funciona intentar comportarse racionalmente: quien trate de calmar a los demás y pretenda frenar la avalancha humana, probablemente resultará víctima de la misma. Lo único razonable, cuando la mayoría se deja arrastrar por la irracionalidad, es imitar a la muchedumbre y dejarse llevar por su empuje. La mayoría malvendió a precios inferiores su inversión, mientras otros tardaron en reaccionar y terminaron perdiendo todo. En el Crac de la Bolsa de Nueva York en 1929, sólo unos pocos muy poderosos pudieron aprovechar la oportunidad, aguantar la crisis, comprar barato y, a la larga, salir fortalecidos de la misma.

\section{Bienvenida la crisis que depurará las costumbres y se llevará lo podrido}

La crisis en la economía virtual se trasladó rápidamente a la economía real. Puesto que los bancos, como reacción a la crisis, restringieron los préstamos muchas empresas se vieron en dificultades. No sólo las que se ofrecían en Bolsa, sino todas las que habían venido operando respaldadas en el crédito bancario y que carecían de liquidez para hacer frente de inmediato a sus acreedores. Éstos a su vez entraban asimismo en dificultades, generando un espiral o círculo vicioso bien conocido y temido por los economistas. En sólo tres años se esfumaron 74 billones de dólares y el desempleo alcanzó 
los ocho millones, una cuarta parte de la población económicamente activa de Estados Unidos. Como la crisis afectó prontamente a otras economías, se volvió mundial. El desmoronamiento europeo en abril de 1931 acompañó al de Estados Unidos, terminando de hundir su economía. En 1932, la tasa de desempleo británica se elevaba al $22.1 \%$ y ascendía al $43.7 \%$ en Alemania. La austeridad empobrecía a la población y proletarizaba a la clase media. Pero había quienes se alegraban de la desesperación reinante: "la gente trabajará más y llevará una vida más moral". "Se purgará así la podredumbre del sistema" decían los conservadores y puritanos, como si la sociedad imitara a la naturaleza: el incendio que un rayo provoca en el bosque, aunque genera destrucción, a la larga le permite regenerarse y renacer con más fuerza. De manera semejante, el razonamiento de los conservadores, aunque en este caso las víctimas no son árboles sino seres humanos. En la depresión el puritanismo reaccionaba así a la época de los felices veinte y sus excesos.

\section{Lo mejor que se puede hacer es no hacer nada}

\section{La ciencia económica clásica se mostraba impotente para} entender lo que estaba pasando e incapaz de dar respuestas. Los economistas educados en los postulados del liberalismo clásico y fieles creyentes en el dogma de que todos los problemas que genera el mercado, el mercado los resuelve, repetían insensatamente que no había que hacer nada. Una vez se hubieran arruinado todas las empresas ineficientes y en crisis, las que quedasen renacerían con fuerza para florecer en un nuevo período de expansión. Nadie era capaz de comprometerse a dar una fecha o decir cuánto tiempo haría falta para que pasase eso, tampoco para aportar soluciones o alivio a la situación desesperada de ocho millones que tras haber perdido sus trabajos, también habían perdido sus viviendas y sus medios de vida. Eran una masa indigente que deambulaba en búsqueda de trabajos eventuales y a expensas de la caridad. Economistas y políticos estaban obligados a proveer vías de acción y traer soluciones a los efectos de una crisis sistémica de la que nadie se hacía responsable.

\section{La fácil receta de Keynes: poner dinero en los bolsillos de los consumidores}

Será considerado como un economista genial, estudiado y admirado por décadas. Sin embargo, las propuestas del economista britá- 
nico John Maynard Keynes podían resumirse en una idea bien simple y sencilla, se trataba de "poner dinero en los bolsillos de la gente", o sea, hacer que el público recuperara un cierto nivel de consumo. Si el Estado le regalara un poco de dinero a todo el mundo, con ese dinero la gente saldría a comprar cosas, empezaría con productos de primera necesidad. Ello reanimaría a las empresas de alimentos, de calzado, ropa, etc. Empezarían a verse anuncios ofreciendo contratar mano de obra. Después seguirían otras empresas, en la medida que más y más personas recuperasen sus trabajos y dispusieran de dinero para su consumo. Es decir, según la estrategia keynesiana, la clave era revertir el movimiento del círculo vicioso y convertirlo en "círculo virtuoso". Claro, como regalar dinero sería criticado por "inmoral" y de políticamente "incorrecto", lo que el Estado debía hacer era dar trabajo a la mayor cantidad de gente posible para pagarles -al final de la semana o de la quincena- e iniciar así el proceso de un aumento de la demanda que iniciara la reactivación. De ahí la propuesta de Keynes de grandes obras públicas - carreteras, presas, puentes- en especial aquéllas que requieren más cantidad de mano de obra. En el fondo no importaba tanto la utilidad, premura o necesidad de tales inversiones - de hecho algunas de las emprendidas en el New Deal eran autopistas cruzando el desierto, en zonas donde bien pocos vehículos pasarían por ellas, o aeropuertos en lugares donde pocos aviones harían uso- pues, lo decisivo era la creación de empleo en el más corto plazo posible.

\section{Lo que conviene al capitalismo no siempre es lo que conviene a los capitalistas}

El sistema se basa en la libre iniciativa de los individuos: quien dispone de un capital decide si lo invierte o no, dónde y cuándo lo hace. No se le puede imponer. El liberalismo espera que gran cantidad de decisiones individuales, cada una de ellas racional desde el punto de vista de cada empresario o inversionista que busca sus propios intereses, generarán una conducta asimismo racional del conjunto. La supuesta racionalidad del sistema se apoyaría en tal supuesto, pero en la realidad no funcionan así las cosas. En especial en tiempos turbulentos y en medio de crisis económicas. En una dinámica de "sálvese quien pueda" predomina la anarquía y el caos y no la "mano invisible" que equilibra las cosas y optimiza los mercados. En tal situación es cuando se hace patente que sólo el Estado puede resolver lo que la iniciativa privada no puede. Por esto es que un planteamiento 
como el keynesiano se aparta del dogmatismo de mercado del "laissez faire” (dejar hacer, sin intromisiones estatales) y se acerca a los enfoques socialdemócratas y/o socialistas de un insustituible protagonismo del Estado para adoptar medidas que enfrenten la crisis y dibujen una hoja de ruta para su superación.

\section{El fascismo, con su modelo de capitalismo de Estado, resultó más exitoso en la recuperación económica que los regímenes liberales}

Ello no debería extrañar, por lo apuntado anteriormente. Mientras en regímenes de democracia liberal, el intrusismo estatal en la esfera de la economía es visto con reparo y provoca resistencias, en cambio, en regímenes de doctrina totalitaria, como es el caso de los fascismos, la iniciativa del Estado es postulada desde la teoría y la doctrina, facilitándose su acción práctica. Además, en la experiencia histórica de Italia y Alemania, el ascenso del fascismo vino acompañado de una política de militarismo que dio un gran empuje a la reactivación económica. Efectivamente, el armamentismo, guerrerismo e imperialismo que se impulsaron como parte de la naturaleza misma del fascismo atrajeron el interés del gran capital y de la gran empresa, coincidían en sus objetivos con las propuestas que desde la política planteaba el
Estado totalitario. Significaba una gran ventaja contar con un solo gran cliente para firmar contratos multimillonarios en una sola ronda de negociación. Es tan así que el sistema de tales países evolucionó a formas de combinación entre capitalismo estatal y privado. El rearme y la modernización militar implicaban grandes pedidos a las industrias, las cuales a su vez demandaban enormes suministros de materias primas, componentes y piezas a otras empresas. Todo ello redundaba en acrecentar el empleo y, con ello, a impulsar el nivel de vida de la población que demandaba otra serie de productos de consumo. De manera parecida funcionó la economía de guerra en Estados Unidos, sacando al país de la depresión con mayor rapidez y efectividad que las políticas keynesianas del New Deal.

\section{La guerra vino a solucionar, con su brutalidad, el estancamiento económico. La economía, por su parte, vendría a determinar el desenlace de la guerra}

No extraña que esa Alemania de 1932 , con más de un $40 \%$ de desempleo, fuera la que le otorgase a Hitler el 10 de abril un $36.8 \%$ de 
los votos, perdió frente al mariscal Hindenburg que consiguió $53 \%$ de la votación por la presidencia. Sin embargo, tras el pacto de la cúpula del partido nazi con la gremial empresarial, el 30 de enero de 1933 conseguía ser nombrado canciller. Desesperados por la crisis económica los unos y atemorizados por el peligro de un triunfo revolucionario los otros confluyeron en dar al demagógico y agresivo caudillo de extrema derecha una correlación suficiente para hacerse con el poder. Lo utilizó con violencia y abuso, pero debe reconocerse su éxito en el terreno económico que le permitió al líder nazi ampliar sus apoyos. La producción de Alemania se había triplicado y había una situación de pleno empleo en 1939. Son triunfos que no supo digerir debidamente el Führer, que ensoberbecido precipitó a su país en la terrible hecatombe que iba a terminar en una enorme catástrofe para Alemania, dolor y destrucción en Europa y el mundo. Alemania no podía ganar, lo demuestran los números. Con sus aliados, Italia y Japón, no llegaba a sumar 200 millones de habitantes, pero se enfrentaba a una masa demográfica de 311 millones, la que sumaba la población de Gran Bretaña, la Unión Soviética y los Estados Unidos, sólo este último país pudo elevar su producción aeronáutica de cerca de 48 mil aviones de guerra en 1942 a 86 mil en 1943 y 96 mil en 1944 . Alemania por su parte sólo pudo incrementar de 15 mil en 1942 a casi 25 mil en 1943 y cerca de 40 mil en 1944. La deuda pública de Estados Unidos pasó de 43 mil millones a 258 mil millones de dólares, llegó a dedicar entre 1941 y 1945 hasta diez veces lo invertido en la Primera Guerra Mundial. Es decir, su gasto militar fue de $320 \mathrm{mil}$ millones de dólares, su superioridad era aplastante.

\section{Igual que en la economía, en la guerra el tamaño sí importa}

Lo comprobó Hitler cuando fracasó en su intento de invadir a la inmensa Rusia. La "Operación Barbarroja" iniciada el 22 de junio de 1941 había sido concebida como una guerra relámpago, debía durar no más de tres meses, pero la gran maquinaria de guerra alemana fracasó ante la inmensidad del reto y las crudas condiciones del invierno ruso. El frente abar- caba 3 mil 200 kilómetros, implicó la movilización de 4 millones de soldados, acuerpados por $10 \mathrm{mil}$ tanques y 5 mil aviones. No cayó Leningrado en octubre, tampoco Moscú en noviembre, vino diciembre y en medio de terribles condiciones climáticas se precipitó la contraofensiva soviética reforzada con 2 millones de hombres que provenían de la región siberiana. Tampoco 
consiguió Hitler tomar Stalingrado en una nueva campaña militar, esta vez hacia el sur, en el verano de 1942. Los campos de petróleo, con los que esperaba movilizar a su ejército y dinamizar su economía, quedaron fuera de su alcance. Contenida la invasión y fijadas las posiciones alemanas, lo que se vino fue la formidable ofensiva soviética que determinó la derrota militar de Alemania. No menos del $80 \%$ de las divisiones acorazadas alemanas y gran parte de sus tropas estaban en el frente ruso. Alrededor de 22 millones de vidas fue el tremendo costo que pagó la Unión Soviética para liberarse del nazismo. El amor a la patria y las convicciones ideológicas del socialismo, pero también las enormes dimensiones de su territorio, de su economía y de su población, fueron determinantes para tal desenlace. La atrasada Rusia, liberada ya de la dictadura del zar, se sobreponía así a la amenaza de sucumbir frente a la terrible dictadura del fascismo. Los pueblos de Europa del Este, liberados por el Ejército Rojo de la bota nazi, quedaban así en una deuda histórica con la Unión Soviética, sería uno de los pilares de la división política de Europa y de la guerra fría que marcaría, en gran medida, a la segunda mitad del siglo XX.

\section{Referencias}

- Benz, W. \& Graml, H. (1986). El siglo XX, (3 volúmenes). México: Siglo XXI.

- Berlin, I. y otros. (1996). Fin de siglo. México: Mc Graw Hill.

- Brower, D. (2002). Historia del mundo contemporáneo, 1900-2001. Madrid: Prentice Hall.

- Fuentes \& LaParra. (2001). Historia universal del siglo XX. De la Primera Guerra Mundial al ataque a las Torres Gemelas. Madrid: Síntesis.

- Hobsbawm E. (2003). Años interesantes. Una vida en el siglo XX. Barcelona: Crítica.

- _ _ (1998). Historia del siglo XX. Barcelona: Crítica.

- Howard, M. (ed.). (1999). Historia Oxford del siglo XX. Barcelona: Planeta.

- Nouschi, M. (1999). Historia del siglo XX: todos los mundos, el mundo. Madrid: Cátedra. 